\title{
I ntracranial translucency as a sonographic marker of open spina bifida at first trimester
}

\author{
Taylan Kara \\ Mersin University Medical Faculty, Department of Radiology, Mersin, Turkey \\ Correspondence: Taylan Kara. Address: Department of Radiology, Mersin University, Mersin, Turkey. Email: \\ taylankara@gmail.com
}

Received: April 10, 2014

Accepted: May 15, $2014 \quad$ Online Published: June 4, 2014

DOI : $10.5430 /$ ijdi.v1n2p92

URL: http://dx.doi.org/10.5430/ijdi.v1n2p92

\section{Abstract}

Spina bifida is the one of the most common severe congenital abnormality of the central nervous system. Scalloping of the frontal bones called "the lemon sign" and caudal displacement of the cerebellum called "the banana sign" are known as cranial signs of open spina bifida on ultrasonography at the second trimester. Although these signs are useful methods in diagnosing of open spina bifida in the second trimester, detection rates of open spina bifida by using these signs in the first trimester are low. Intracranial translucency is a new sonographic landmark that may be valuable for the early detection of open spina bifida in the first trimester.

In this study using of intracranial translucency as a sonographic marker of open spina bifida at first trimester is discussed with the light of recent literature.

\section{Keywords}

Intracranial translucency, Open spina bifida, Ultrasonography, Marker

\section{Introduction}

Spina bifida is the one of the most common severe congenital abnormality of the central nervous system ${ }^{[1]}$. Although different terminologies are used, commonly accepted categories are open spina bifida (nervous tissue or meninges exposed to the enviroment) and closed spina bifida (skin-closed dysraphism) ${ }^{[1]}$. The prognosis is poorer in cases with open spina bifida than those with closed spina bifida and many patients with closed spina bifida are asymptomatic ${ }^{[2-4]}$. So diagnosis of open spina bifida is essential especially for the future management of this entity.

The main method of screening of open spina bifida was by maternal serum alpha-fetoprotein at around 16th gestational weeks in the $1980 \mathrm{~s}^{[5]}$. Spinal defects may be detected directly on ultrasonography (US), however it is hard to visualize spine defects in second trimester. Detection of cranial markers of spinal defects are more easier than detection of spine defects. Also visualization of spine defects in first trimester is harder than those in second trimester.

Scalloping of the frontal bones called "the lemon sign" and caudal displacement of the cerebellum called "the banana sign" are known as cranial signs of open spina bifida on US at the second trimester ${ }^{[6]}$. By the findings of cranial signs in fetuses with open spina bifida, US could lead to detect open spina bifida with high accuracy in the second trimester. 
There are also some other cranial markers such as parallel cerebral peduncles and acorn-shaped cranium that have been reported in the literature ${ }^{[7]}$.

Although these signs are useful methods in diagnosing of open spina bifida in the second trimester, detection rates of open spina bifida by using these signs in the first trimester are low. In a study with 61972 singleton pregnancies including 29 cases of spina bifida, US can detect $97 \%$ of cases with spina bifida in the second trimester ${ }^{[8]}$. Interestingly none of the cases with spina bifida was diagnosed at the routine first-trimester scan at 10-14 weeks.

\section{Methods}

Intracranial translucency (IT) is a new sonographic landmark that may be valuable for the early detection of open spina bifida in the first trimester.

IT can be visualized in the standard midsagittal plane used for measurement of the nuchal translucency and evaluation of the nasal bone. The image should be magnified to include only the fetal head and upper thorax as the same as in the measurement of nuchal translucency.

In this position Chaoui et al describe that the fourth ventricle is seen as an intracranial translucency, delineated by two echogenic borders; the dorsal part of the brain stem anteriorly and the coroid plexus of the fourth ventricle posteriorly ${ }^{[5]}$ (see Figure 1).

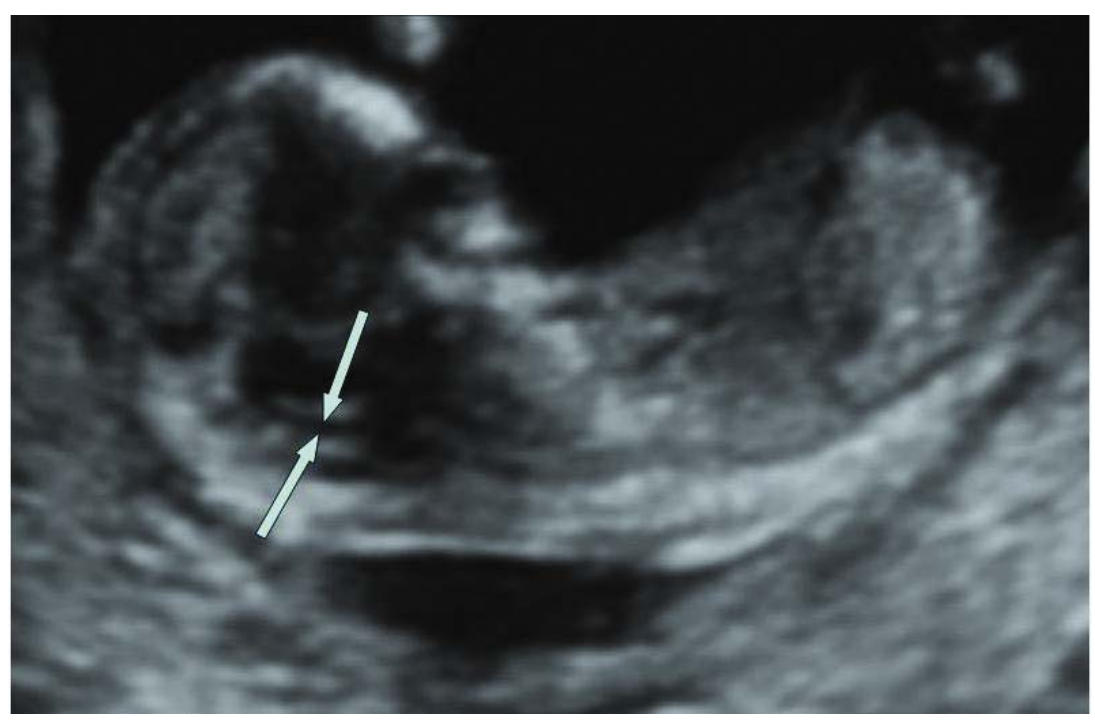

Figure 1. Ultrasound image in the mid-sagittal plane of the fetus showing intracranial translucency (arrows).

The optimal gestational age for measurement of IT is 11 week to $13+6$ weeks. Although IT can be visualized both transabdominally and transvaginally, on transvaginal US contrast discrimination between the IT and surrounding brain is poorer than that of mid-sagittal planes of the face obtained transabdominally ${ }^{[9]}$.

The fourth ventricle can be detected easily in the developing human fetuses from 8 weeks described as a hypoechoic structure on sonography ${ }^{[10]}$. IT is the largest anteroposterior diameter of the fourth ventricle in the mid-sagittal position. Cisterna cerebellomedullaris known as cisterna manga is the thin translucency that can be seen between IT and occipital bone (see Figure 2). 


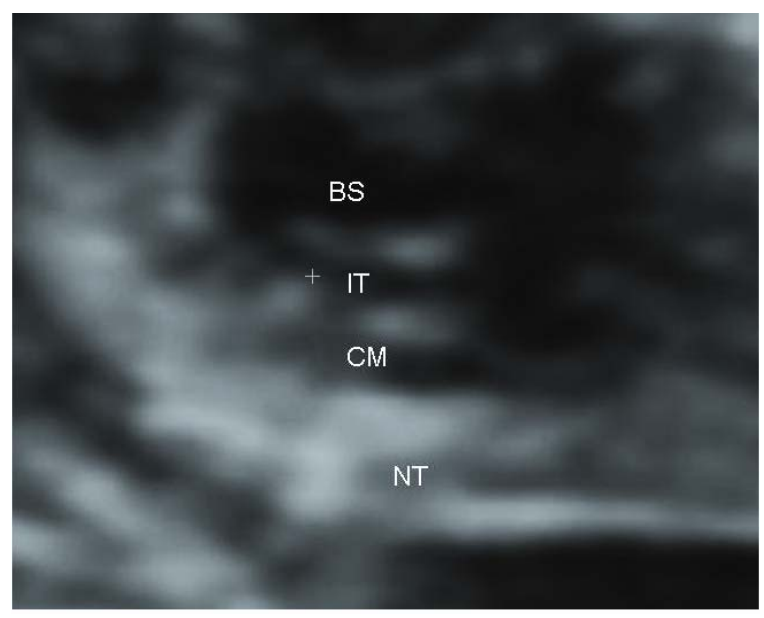

Figure 2. Magnified image of the fetus showing nuchal translucency (NT), cisterna manga (CM), intracranial translucency (IT) and brain stem (BS).

\section{Discussion}

Open spina bifida is associated with Arnold-Chiari II malformation as the consequence of leakage of cerebrospinal fluid into the amniotic cavity and hypotension in the subarachnoid space which leads to caudal displacement of the brain stem and obliteration of the cisterna cerebellomedullaris (cisterna magna) ${ }^{[3,8,11,12]}$.

As a result of this mechanism absence of the IT is seen in the fetuses with open spina bifida. A study included 199 fetuses reports that if IT is seen confidently, open spina bifida can be excluded ${ }^{[13]}$. However the rate of open spina bifida is only $50 \%$ in the fetuses in which IT is not seen. Non-visibility of IT is also attributed to inadequate images.

In a study including 990 fetuses Adiego et al reported that the mean IT anteroposterior diameter was $1.8 \mathrm{~mm}$ (range 0.8-3.1) ${ }^{[14]}$. In another study including 201 singleton fetuses median IT value for the first trimester was $1.7 \mathrm{~mm}$ (range 1-2.4) ${ }^{[15]}$. In another study including 102 normal fetuses IT at first trimester ranged from 1.35 to $2.6 \mathrm{~mm}$ by using three-dimensional US in Chinese population ${ }^{[16]}$.

IT value is directly proportional with crown-rump length. Visualization of IT is significantly associated with crown-rump length, gestational age, maternal weight, and fetal position ${ }^{[17]}$.

Fetal position is one of the most important factor for evaluation of IT. IT of fetuses can evaluate more effective in supine position than prone position. In a study including 191 fetuses, IT was visualized as 82\% (146/178) among fetuses with supine position, however in fetuses with prone position IT was visualized only as $31 \%(4 / 13){ }^{[13]}$. So it can be said that supine position is more accurate for evaluation of IT.

The other factor that effects the visualization of IT is maternal weight on abdominal US. Visualization rate of IT decreases in patients with high body mass index on transabdominal approach. So for improving the visualization rate of IT, it should be better to use transvaginal US in this group of patients. Beamon et al reported that maternal race was not significantly associated with visualization of IT $^{[17]}$.

In accordance with previous reports, IT may increase linearly with advancing CRL. Additionally, these studies reported nomograms of intracranial translucency in the first trimester. 
IT can be assessed using the semiautomated measurement or manually. Although intraobserver and interobserver differences are reported in the manuel measurement of IT, manuel IT measurements are found reproductible ${ }^{[18]}$. Specific training of the sonographers also improves the visualization rate of IT $^{[19]}$.

For accurate evaluation of IT there is not any learning curve that has been published before. However College Français d'Echographie Foetale (CFEF) has developed a specific score for IT visualization similar to the nuchal translucency using the eight anatomic landmarks: visualization of the thalamus, the midbrain, the brain stem, the posterior wall of the brain stem, the fourth ventricle, the choroid plexus of the fourth ventricle, the spine ${ }^{[19]}$.

According to these criteria, each criterion is scored as satisfactory (1) or insufficient (0), maximum possible score is 8 .

The image settings are also affect IT identification and measurement. Zhen et al reported that increased gain and reduced contrast are the most influential factors and may cause under-measurement of IT ${ }^{[20]}$.

The optimal gestational age for measurement of IT is 11 week to $13+6$ weeks. Although IT can be visualized both transabdominally and transvaginally, on transvaginal US contrast discrimination between the IT and surrounding brain is poorer than that of mid-sagittal planes of the face obtained transabdominally ${ }^{[9]}$. Three-dimensional US can also be used as a reliable technique for measuring IT $^{[21]}$.

Although using of IT is mainly focused on the detection of open spina bifida there are several pathologies can cause the alteration of IT. Papastefanou et al reported that IT increases in fetuses with chrosomal abnormalities ${ }^{[22]}$. However number of chromosomally abnormal fetuses including in this study is very small. So further studies should be needed to show IT as a marker of chromosomal abnormalities.

Buitrago-Leal et al reported that alteration of IT is related not only just neural tube defects but also posterior fossa anomalies ${ }^{[23]}$. Some articles have been published for Dandy Walker syndromes as a reason of enlarged IT ${ }^{[24-26]}$. Iuculano et al reported a case of enlarged IT with Blake`s pouch cyst ${ }^{[27]}$.

The first study about IT in using the diagnosis of open spina bifida was reported in 2009. So using IT as a marker of open spina bifida at first trimester is relatively a new method. Datas on sensitivity and specificity are still needed. IT is requested as a screening marker on ultrasonography. Visualization of IT is a valuable screening test especially when it is normal, however a negative IT is not accurate enough to detect an open spina bifida because a lot of parameters such as pitfalls, fetal positions and technical reasons may effect the visualization of IT.

Depending on the limited literature since today IT may be a useful method in screening open spina bifida. Large prospective studies will give more accurable information about the value of IT.

\section{References}

[1] Tortori-Donati P,Rossi A,Cama A. Spinal dysraphism: a review of neuroradiological features with embryological correlations and proposal for a new classification. Neuroradiology. 2000; 42: 471-491. http://dx.doi.org/10.1007/s002340000325

[2] Bowman RM, McLone DG, Grant JA, Tomita T, Ito JA. Spina bifida outcome: A 25-year prospective. Pediatr Neurosurg. 2001; 34(3): 114-20. http://dx.doi.org/10.1159/000056005

[3] Oakeshott P, Hunt GM, Poulton A, Reid F. Open spina bifida: Birth findings predict long-term outcome. Arch Dis Child. 2012; 97(5): 474-6. http://dx.doi.org/10.1136/archdischild-2011-300624

[4] Boone D, Parsons D, Lachmann SM, Sherwood T. Spina bifida occulta: lesion or anomaly? Clin Radiol. 1985; 36(2): 159-61. http://dx.doi.org/10.1016/S0009-9260(85)80100-8

[5] Chaoui R, Benoit B, Mitkowska-Wozniak H, Heling KS, Nicolaides KH.Assessment of intracranial translucency (IT) in the detection of spina bifida at the 11-13-week scan. Ultrasound Obstet Gynecol. 2009; 34: 249-252.

http://dx.doi.org/10.1002/uog.7329

Published by Sciedu Press 
[6] Nicolaides KH, Campbell S, Gabbe SG, Guidetti R. Ultrasound screening for spina bifida: cranial and cerebellar signs. Lancet. 1986; 2: 72-74. http://dx.doi.org/10.1016/S0140-6736(86)91610-7

[7] Buisson O, De Keersmaecker B, Senat MV, Bernard JP, Moscoso G, Ville Y. Sonographic diagnosis of spina bifida at 12 weeks: Heading towards indirect signs. Ultrasound Obstet Gynecol. 2002; 19: 290-292. http://dx.doi.org/10.1046/j.1469-0705.2002.00660.x

[8] Sebire NJ, Noble PL, Thorpe-Beeston JG, Snijders RJ, Nicolaides KH. Presence of the 'lemon' sign in fetuses with spina bifida at the 10-14-week scan. Ultrasound Obstet Gynecol. 1997; 10: 403-405. http://dx.doi.org/10.1046/j.1469-0705.1997.10060403.x

[9] Chaoui R, Nicolaides KH. From nuchal translucency to intracranial translucency: Towards the early detection of spina bifida. Ultrasound Obstet Gynecol. 2010; 35: 133-138. http://dx.doi.org/10.1002/uog.7552

[10] Blaas HG, Eik-Nes SH. Sonoembryology and early prenatal diagnosis of neural anomalies.Prenat Diagn. 2009; 29 : 312-325. http://dx.doi.org/10.1002/pd.2170

[11] Lachmann R, Chaoui R, Moratalla J, Picciarelli G, Nicolaides KH. Posterior brain in fetuses with open spina bifida at 11 to 13 weeks. Prenat Diagn. 2011; 31: 103-106. http://dx.doi.org/10.1002/pd.2632

[12] Ghi T, Pilu G, Falco P, Segata M, et al. Prenatal diagnosis of open and closed spina bifida. Ultrasound Obstet Gynecol. 2006; 28: 899-903. http://dx.doi.org/10.1002/uog.3865

[13] Fong KW, Toi A, Okun N, Al-Shami E, Menezes RJ. Retrospective review of diagnostic performance of intracranial translucency in detection of open spina bifida at the 11-13-week scan. Ultrasound Obstet Gynecol. 2011; 38: 630-634. http://dx.doi.org/10.1002/uog.8994

[14] Adiego B, Illescas T, Martinez-Ten P, et al. Intracranial translucency at 11-13 weeks of gestation: prospective evaluation and reproducibility of measurements. Prenat Diagn. 2012; 32: 259-263. http://dx.doi.org/10.1002/pd.2944

[15] Ergin RN, Yayla M. The nomogram of intracranial translucency in the first trimester in singletons. J Turk Ger Gynecol Assoc.2012; 13(3): 153-6. http://dx.doi.org/10.5152/jtgga.2012.19

[16] Chen M, Chen H, Yang X, Wang HF, Yeung Leung T, Singh Sahota D, et al. Normal range of intracranial translucency (IT) assessed by three-dimensional ultrasound at $11+0$ to $13+6$ weeks in a Chinese population. J Matern Fetal Neonatal Med. 2012; 25: 489-492. http://dx.doi.org/10.3109/14767058.2011.599455

[17] Beamon CJ, Stuebe AM, Wolfe HM. Factors Influencing Visualization of the Intracranial Translucency during First-Trimester Screening for Aneuploidy. Am J Perinatol. 2012; 29: 503-508.

[18] Karl K, Kagan KO, Chaoui R. Intra- and interoperator reliability of manual and semi-automated measurements of intracranial translucency. Ultrasound Obstet Gynecol. 2012; 39: 164-168. http://dx.doi.org/10.1002/uog.10137

[19] Mangione R, Lelong N, Fontanges M, et al. Visualization of intracranial translucency at the 11-13-week scan is improved after specific training. Ultrasound Obstet Gynecol. 2011; 38: 635-639. http://dx.doi.org/10.1002/uog.10118

[20] Zhen L, Yang X, Ting YH, Chen M, Leung TY. The influence of image setting on intracranial translucency measurement by manuel and semi-automated system. Prenatal diagnosis 2013: 33; 889-893. http://dx.doi.org/10.1002/pd.4154

[21] Lee MY, Won HS, Jeong BD, Hyun MK,Lee HY, Shim JY, et al. Measurement of intracranial translucency using three-dimensional ultrasound and Volume IT ${ }^{\mathrm{TM}}$. Prenat Diagn. 2012; 32:472-475. http://dx.doi.org/10.1002/pd.3842

[22] Papastefanou I, Souka AP, Pilalis A, Panagopoulos P, Kassanos D. Fetal intracranial translucency and cisterna magna at 11 to 14 weeks: Reference ranges and correlation with chromosomal abnormalities. Prenat Diagn. 2011; 31:1189-1192.

[23] Buitrago-Leal M, Molina-Giraldo S. Use of intracranial translucency measurement in first trimester, beyond spina bifida. Ginecol Obstet Mex. 2014: 82; 20-31.

[24] Nizard J, Bernard JP, Ville Y. Fetal cystic malformations of the posterior fossa in the first trimester of pregnancy. Fetal Diagn Ther.2005; 20(2): 146-51. http://dx.doi.org/10.1159/000082440

[25] Lachmann R, Sinkovskaya E, Abuhamad A. Posterior brain in fetuses with Dandy-Walker malformation with complete agenesis of the cerebellar vermis at 11-13 weeks: a pilot study. Prenat Diagn.2012; 32(8): 765-9. http://dx.doi.org/10.1002/pd.3899

[26] Lee MY,Won HS,Hyun MK,Lee HY,Shim JY,Lee PR,et al. One case of increased intracranial translucency during the first trimester associated with the Dandy-Walker variant. Prenat Diagn.2012; 32(6): 602-3. http://dx.doi.org/10.1002/pd.3868

[27] Iuculano A,Zoppi MA,Ibba RM,Monni G. A Case of Enlarged Intracranial Translucency in a Fetus with Blake's Pouch Cyst. Case Rep Obstet Gynecol. 2014; 2014: 968089. 